\title{
Oxidation Resistive Cu Films by Room Temperature Surface Passivation with Thin Ag Layer
}

\author{
Jae Jeong Kim,*,z Yong Shik Kim,** and Soo-Kil Kim** \\ Research Center for Energy Conversion and Storage, School of Chemical Engineering, \\ College of Engineering, Seoul National University, Kwanak-gu, Seoul 151-742, Korea
}

\begin{abstract}
A displacement-deposited $\mathrm{Ag}$ layer was investigated as an oxidation barrier in damascene $\mathrm{Cu}$ structure for high performance interconnection. A $40 \mathrm{~nm}$ thick bright and continuous Ag film was formed at the surface of electrodeposited $\mathrm{Cu}$ by immersing the copper film into the silver displacement solution. The $\mathrm{Ag}$ film at $\mathrm{Cu}$ surface significantly blocked oxygen diffusion into the $\mathrm{Cu}$ film and retarded oxidation. More importantly, an elevated barrier performance for oxygen diffusion through elimination and stuffing of grain boundaries of $\mathrm{Cu}$ was observed upon annealing in a $400^{\circ} \mathrm{C} \mathrm{N}_{2}$ atmosphere. Outward $\mathrm{Cu}$ diffusion through Ag layer controlled $\mathrm{Cu}$ oxidation when the surface was passivated with Ag layer. (C) 2002 The Electrochemical Society. [DOI: 10.1149/1.1534732] All rights reserved.
\end{abstract}

Manuscript submitted August 25, 2002; revised manuscript received October 25, 2002 Available electronically December 10, 2002.

Copper's low resistivity and good electromigration property make it an ideal substitute for a conventional aluminum alloy as an interconnection material. ${ }^{1,2}$ However, copper film cannot form a self-passivation layer under oxidizing conditions. Likewise, it is readily oxidized to cuprous or cupric oxide once exposed to air. Copper oxide is a semiconducting material with higher resistivity than pure copper. Thus, passivation of exposed copper film surface under oxidizing conditions is an important issue in the copper metallization processes.

Various attempts have been made to solve this problem, including ion implantation, ${ }^{3-5}$ formation of surface silicides, ${ }^{6}$ bilayer annealing, ${ }^{7}$ and alloying the copper with $\mathrm{Al}$ or $\mathrm{Mg} .{ }^{8-10}$ Doping with $\mathrm{Al}$ or $\mathrm{Mg}$ is considered as the best method. This method includes the codeposition of $\mathrm{Cu}$ with $\mathrm{Al}$ or $\mathrm{Mg}$. It can be performed easily using the physical vapor deposition (PVD) process. However, it is difficult to alloy copper with $\mathrm{Al}$ or $\mathrm{Mg}$ using other deposition methods such as chemical vapor deposition (CVD) or electrodeposition, whereby copper metallization in damascene structure is implemented due to its own superfilling capability. In particular, codeposition of $\mathrm{Cu}$ with $\mathrm{Al}$ or $\mathrm{Mg}$ during aqueous acidic $\mathrm{Cu}$ electrodeposition is essentially forbidden since $\mathrm{Al}$ and $\mathrm{Mg}$ cannot be deposited from aqueous solution. ${ }^{11}$ Accordingly, it is necessary to develop a new passivation method that is compatible with the present damascene process.

In this study, a thin Ag film was deposited onto exposed $\mathrm{Cu}$ surface using the galvanic displacement deposition method. During galvanic displacement deposition, electrons are supplied through the dissolution of substrate $\mathrm{Cu}$ metal to convert the $\mathrm{Ag}^{+}$in the aqueous solution into Ag. Therefore, after chemical mechanical planarization (CMP) in the damascene process, this galvanic displacement deposition method can be used for $\mathrm{Cu}$ surface-selective passivation method. Figure 1 presents a schematic illustration of this process. This study examined the effect of Ag galvanic displacement deposition and annealing on the resistance to oxidation of electrodeposited $\mathrm{Cu}$ film.

\section{Experimental}

The study used $\mathrm{Cu}$ (seed, $70 \mathrm{~nm}$ )/TiN, $10 \mathrm{~nm} / \mathrm{Ti}, 15 \mathrm{~nm} / \mathrm{Si}$ as substrate structure. $\mathrm{Cu}$ and TiN was deposited through hollow cathode magnetron (HCM) PVD and metallorganic chemical vapor deposition (MOCVD), respectively. Four different kinds of samples were prepared from this substrate to test oxidation resistance: (a) electrodeposited copper, (b) annealed electrodeposited copper, (c) silver-passivated electrodeposited copper, and (d) annealed silverpassivated electrodeposited copper (Table I). Prior to electrodeposi-

\footnotetext{
* Electrochemical Society Active Member.

** Electrochemical Society Student Member.

z E-mail: jjkimm@snu.ac.kr
}

tion onto the $\mathrm{Cu}$ seed layer, the substrate was pretreated with a 1:200 $\mathrm{NH}_{4} \mathrm{OH}$ solution for $30 \mathrm{~s}$ to remove the native copper oxide. ${ }^{12}$ Each wafer was then rinsed with deionized (DI) water and dried in an $\mathrm{N}_{2}$ stream. The electrolyte for copper deposition was composed of 0.2 $\mathrm{mol} / \mathrm{L} \mathrm{CuSO}_{4}$ and $1.0 \mathrm{~mol} / \mathrm{L} \mathrm{H}_{2} \mathrm{SO}_{4}$. Cu bar and saturated calomel electrode (SCE) were used as counter electrode and reference electrode, respectively. Copper was deposited at a constant $-0.2 \mathrm{~V}$, which is optimized to the electrolyte, using a PAR 263 potentiostat (EG\&G Princeton Applied Research Corporation). The $\mathrm{Cu}$ film electrodeposited for $400 \mathrm{~s}$ was about $1000 \mathrm{~nm}$ thick.

The solution for $\mathrm{Ag}$ galvanic displacement deposition was composed of $0.059 \mathrm{~mol} / \mathrm{L} \mathrm{AgNO}_{3}, 0.58 \mathrm{~mol} / \mathrm{L}\left(\mathrm{NH}_{4}\right)_{2} \mathrm{SO}_{4}$, and 523 $\mathrm{mL} / \mathrm{L} \mathrm{NH}_{4} \mathrm{OH}$, that were used to supply $\mathrm{Ag}$ ions, adjust $\mathrm{pH}$, and dissolve the $\mathrm{Cu}$ film, respectively. A thin Ag layer was deposited on an electrodeposited copper layer by dipping the sample into the $\mathrm{Ag}$ solution for $20 \mathrm{~s}$. Annealing was done at $400^{\circ} \mathrm{C}$ for $30 \mathrm{~min}$ in an $\mathrm{N}_{2}$ stream. ${ }^{13}$ The oxidation of four different kinds of samples was induced at $300^{\circ} \mathrm{C}$ for 4,9 , and $25 \mathrm{~min}$. The oxidation resistance of each sample was then compared according to oxide thickness and change in sheet resistance. Oxide thickness and change in sheet resistance were measured using field emission scanning electron microscopy (FESEM) and four-point probe, respectively. On the other hand, X-ray diffraction (XRD) and Auger electron spectroscopy (AES) were used to analyze the crystallinity and oxygen contents of the samples.

\section{Results and Discussion}

Displacement of $\mathrm{Cu}$ with $\mathrm{Ag}$ occurred spontaneously upon immersion of $\mathrm{Cu}$ film into the displacement solution. The following reaction results in the formation of uniform and shiny $\mathrm{Ag}$ layer coating on $\mathrm{Cu}$ film

$$
\mathrm{Cu}(\mathrm{s})+2 \mathrm{AgNO}_{3}(\mathrm{aq}) \rightarrow \mathrm{Cu}\left(\mathrm{NO}_{3}\right)_{2}+2 \mathrm{Ag}(\mathrm{s})
$$

Figure 2 shows the AES depth profile and XRD spectra of a displacement-deposited Ag layer on $\mathrm{Cu}$ film. Displacement for $20 \mathrm{~s}$ produced a $40 \mathrm{~nm} \mathrm{Ag}$ layer deposition. Both the $\mathrm{Cu}$ and $\mathrm{Ag}$ are face centered cubic (fcc) structures with similar lattice parameters of 361.49 and $408.53 \mathrm{pm}$, respectively. The reaction stoichiometry and lattice parameters indicate that the $40 \mathrm{~nm}$ Ag layer was deposited at the expense of about $18 \mathrm{~nm} \mathrm{Cu}$ layer from the surface. Figure $2 \mathrm{a}$ clearly shows that the deposited Ag layer is very thin and surfacerestricted. The texture of the deposited $\mathrm{Ag}$ layer showed a very strong (111) peak (Fig. 2b), which indicates a strong texture inheritance from the underlying $\mathrm{Cu}$ layer. Since these two metals are highly conductive and the major conductor is the underlying thicker $\mathrm{Cu}$ film, the sheet resistance after the displacement reaction was reduced by around $2 \%$.

To investigate the oxidation resistance of $\mathrm{Cu}$ films, four samples assigned as a to $\mathrm{d}$ in the experimental section were used. Oxidation was performed at $300^{\circ} \mathrm{C}$ atmospheric condition for 4, 9, and $25 \mathrm{~min}$. 

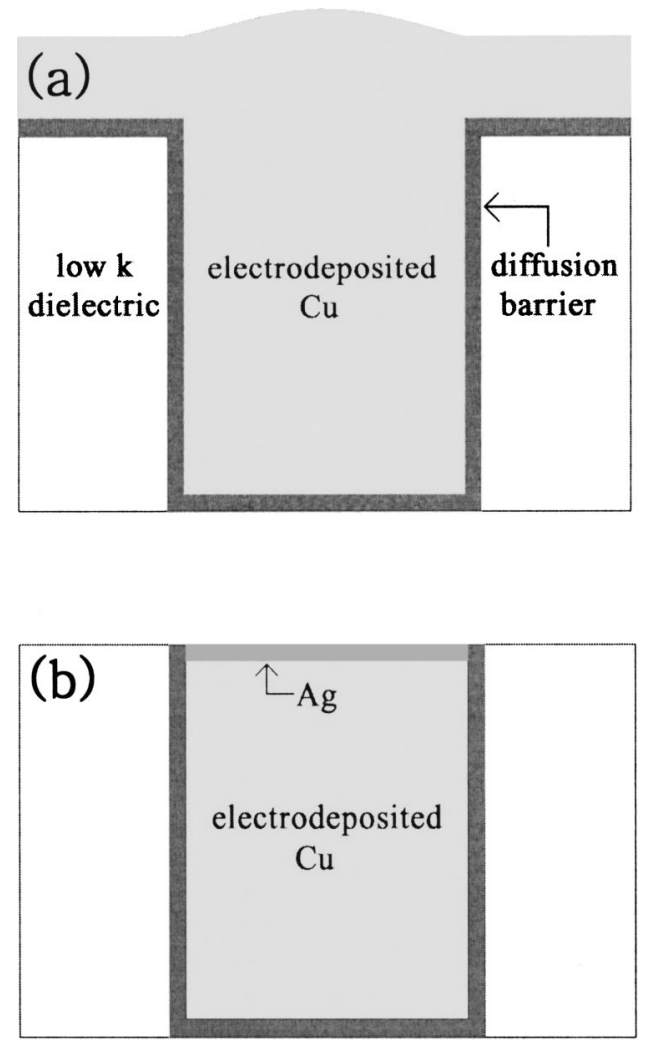

Figure 1. Schematic illustrations of (a) as-deposited damascene $\mathrm{Cu}$ structure and (b) surface passivated $\mathrm{Cu}$ after CMP and Ag displacement deposition.

Figure 3 presents the changes in sheet resistance according to oxidation time. $R_{\mathrm{O}}$ and $R_{\mathrm{S}}$ are sheet resistances of as-prepared and after oxidation, respectively. Sample a with $\mathrm{Cu} / \mathrm{TiN} / \mathrm{Ti} / \mathrm{Si}$ structure and without annealing showed a drastic increase in sheet resistance. Though the copper oxide is a semiconducting material it has a much higher resistivity than pure $\mathrm{Cu}$, which is the reason for increase in sheet resistance after oxidation. A slight improvement in oxidation resistance was observed when the sample $\mathrm{Cu} / \mathrm{TiN} / \mathrm{Ti} / \mathrm{Si}$ was annealed prior to oxidation (Fig. 3b). Regardless of annealing, oxidation of the $\mathrm{Cu}$ layer was significantly inhibited by the capping of $\mathrm{Cu}$ surface with $40 \mathrm{~nm}$ thick Ag layer (Fig. $3 \mathrm{c}$ and d). In the case of the annealed $\mathrm{Ag} / \mathrm{Cu} / \mathrm{TiN} / \mathrm{Ti} / \mathrm{Si}$ structure $\mathrm{d}$, resistance to oxidation was higher compared to the case without annealing (Fig. 3c). This implies that heat-induced changes in microstructure contributed to oxidation resistance.

Figure 4 shows the cross-sectional FESEM images of the four types of samples and corresponding AES depth profiles after oxidation for $9 \mathrm{~min}$. Since the thermal expansion coefficient of pure copper was about two to eight times higher than that of copper oxide and silicon $\left(0.23,0.03,0.12 / 0.07 / 0.07\right.$, and $0.03 \times 10^{-4} / \mathrm{K}$ for $\mathrm{Cu}$,

\begin{tabular}{|c|c|c|}
\hline Sample & Structure & Processes \\
\hline $\mathrm{a}$ & $\mathrm{Cu} / \mathrm{TiN} / \mathrm{Ti} / \mathrm{Si}$ & $\mathrm{Cu}$ electrodeposition \\
\hline $\mathrm{b}$ & Annealed $\mathrm{Cu} / \mathrm{TiN} / \mathrm{Ti} / \mathrm{Si}$ & $\begin{array}{c}\mathrm{Cu} \text { electrodeposition } \\
\rightarrow \text { anneal }\end{array}$ \\
\hline $\mathrm{c}$ & $\mathrm{Ag} / \mathrm{Cu} / \mathrm{TiN} / \mathrm{Ti} / \mathrm{Si}$ & $\begin{array}{l}\mathrm{Cu} \text { electrodeposition } \\
\rightarrow \text { Ag displacement } \\
\quad \text { deposition }\end{array}$ \\
\hline $\mathrm{d}$ & Annealed Ag/Cu/TiN/Ti/Si & $\begin{array}{l}\text { Cu electrodeposition } \\
\rightarrow \text { Ag displacement } \\
\text { deposition } \rightarrow \text { anneal }\end{array}$ \\
\hline
\end{tabular}
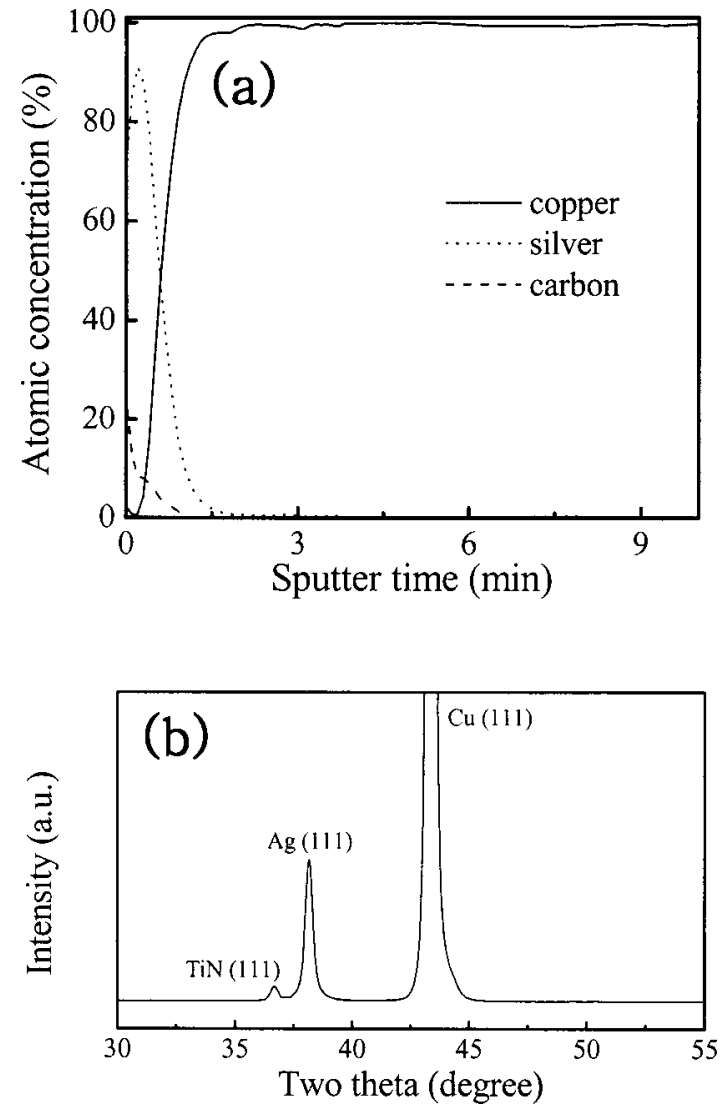

Figure 2. (a) AES depth profile of Ag displacement-deposited $\mathrm{Cu}$ film and (b) its XRD spectra.

$\mathrm{Cu}_{2} \mathrm{O}, \mathrm{CuO}$ (monoclinic, $\mathrm{a} / \mathrm{b} / \mathrm{c}$ ), and $\mathrm{Si}$, respectively), the thermal oxidation and cooling process resulted in cracks between each layer. Thus, the FESEM images define the boundaries between pure copper and oxidized copper. Similar phenomena regarding cracks between copper and its oxide was reported in another study. ${ }^{14}$ Almost all $\mathrm{Cu}$ in sample a was oxidized after 9 min thermal oxidation resulting in a very thin $\mathrm{Cu}$ film just above the TiN barrier layer. For the annealed sample b, the oxidation of copper was retarded com-

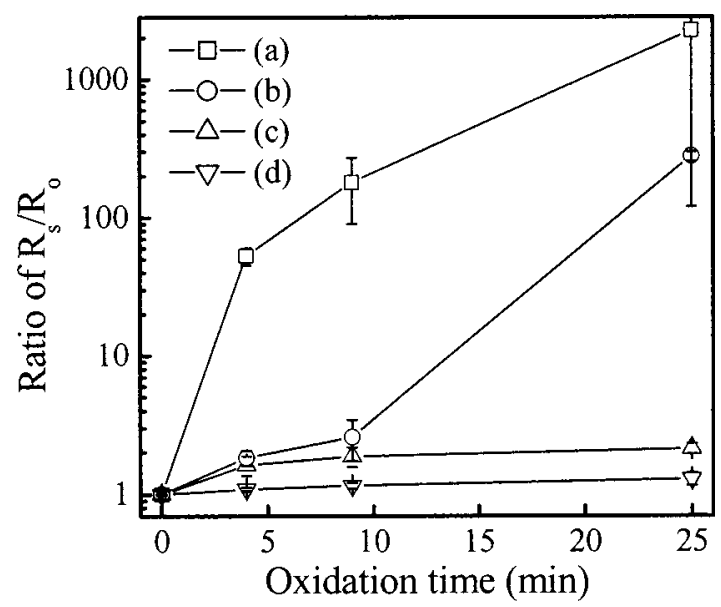

Figure 3. Sheet resistance changes of four types of samples according to the oxidation time; (a) $\mathrm{Cu} / \mathrm{TiN} / \mathrm{Ti} / \mathrm{Si}$, (b) annealed $\mathrm{Cu} / \mathrm{TiN} / \mathrm{Ti} / \mathrm{Si}$, (c) $\mathrm{Ag} / \mathrm{Cu} / \mathrm{TiN} / \mathrm{Ti} / \mathrm{Si}$, and (d) annealed $\mathrm{Ag} / \mathrm{Cu} / \mathrm{TiN} / \mathrm{Ti} / \mathrm{Si}$. $\left(R_{\mathrm{s}}\right.$ : sheet resistance after oxidation, $R_{\mathrm{o}}$ : sheet resistance of as-prepared.) 

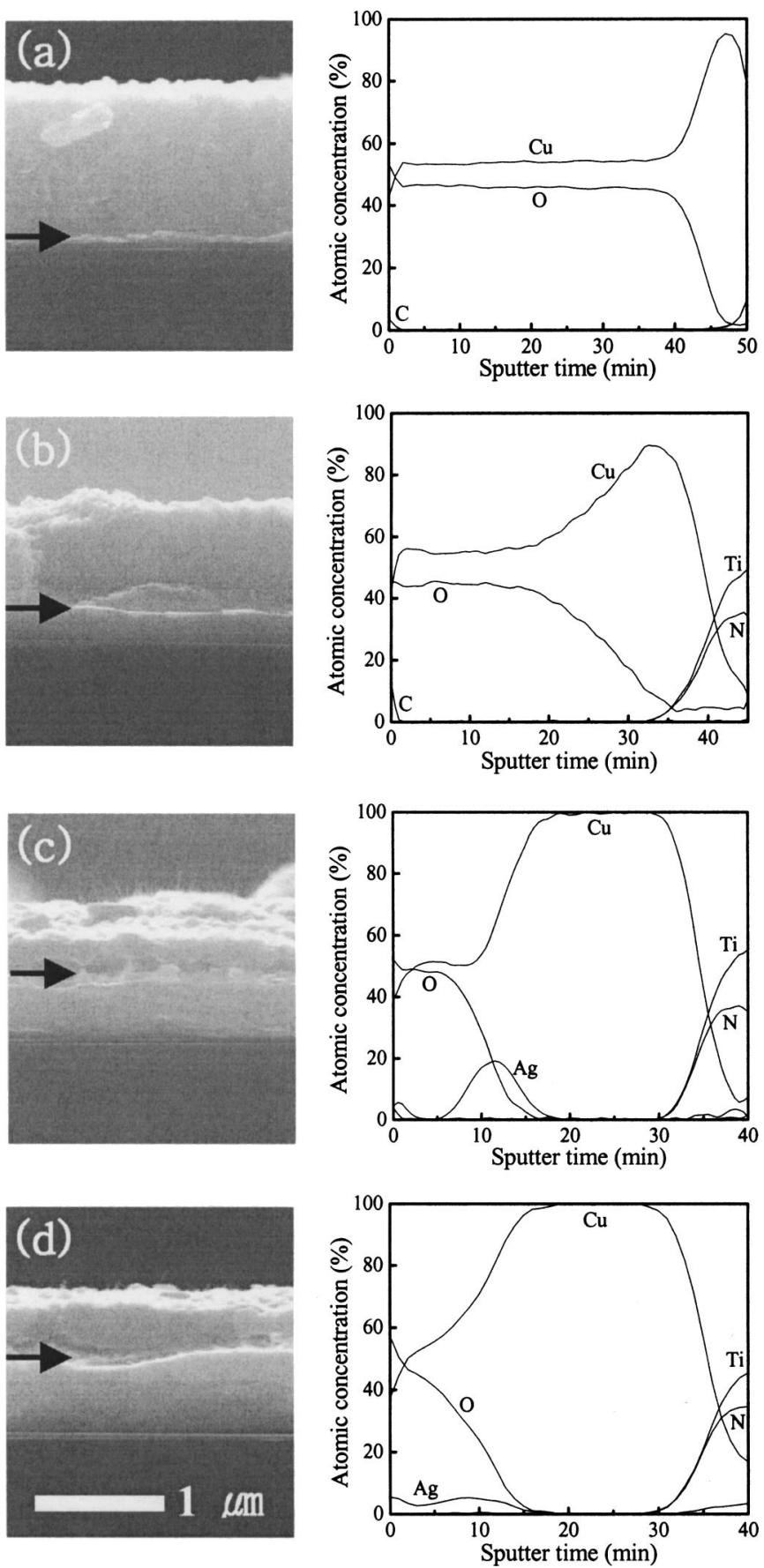

Figure 4. Cross-sectional FESEM images and corresponding AES depth profiles of four types of samples after $9 \mathrm{~min}$ oxidation at $300^{\circ} \mathrm{C}$ atmospheric conditions; (a) $\mathrm{Cu} / \mathrm{TiN} / \mathrm{Ti} / \mathrm{Si}$, (b) annealed $\mathrm{Cu} / \mathrm{TiN} / \mathrm{Ti} / \mathrm{Si}$, (c) $\mathrm{Ag} / \mathrm{Cu} / \mathrm{TiN} / \mathrm{Ti} / \mathrm{Si}$, and (d) annealed $\mathrm{Ag} / \mathrm{Cu} / \mathrm{TiN} / \mathrm{Ti} / \mathrm{Si}$.

pared to sample a. Nonoxidized $\mathrm{Cu}$ layers of samples $\mathrm{c}$ and $\mathrm{d}$ were much thicker than those without $\mathrm{Ag}$ passivation layer after thermal oxidation. The AES depth profiles of samples $\mathrm{c}$ and d show that the $\mathrm{Ag}$ profile was somewhat different from that of the as-plated $\mathrm{Ag}$ presented in Fig. 2a. In sample c, the Ag layer after thermal oxidation was positioned at an interface between pure copper and copper oxide. This implies that the Ag passivation layer served as a diffusion barrier of oxygen and copper to prevent interaction between them and that the outward diffusion of $\mathrm{Cu}$ through the $\mathrm{Ag}$ layer is preferred to that of the atmospheric oxygen to within the film. In sample d, a slight increase in pure $\mathrm{Cu}$ thickness was observed. $\mathrm{Ag}$

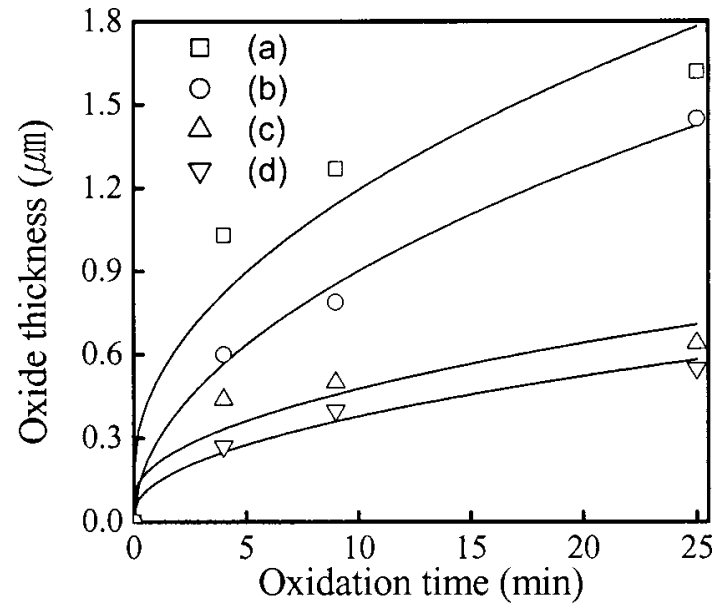

Figure 5. Oxide thickness of four types of samples according to oxidation time; (a) $\mathrm{Cu} / \mathrm{TiN} / \mathrm{Ti} / \mathrm{Si}$, (b) annealed $\mathrm{Cu} / \mathrm{TiN} / \mathrm{Ti} / \mathrm{Si}$, (c) $\mathrm{Ag} / \mathrm{Cu} / \mathrm{TiN} / \mathrm{Ti} / \mathrm{Si}$, and (d) annealed $\mathrm{Ag} / \mathrm{Cu} / \mathrm{TiN} / \mathrm{Ti} / \mathrm{Si}$.

distribution within the film was also very broad compared to the narrow profile in c. This indicates that heat-induced (annealing) changes in film structure improved the function of $\mathrm{Ag}$ layer as a diffusion barrier.

Oxidation of pure copper and its progress are determined through oxygen diffusion within the copper film. In particular, one of the most important diffusion paths is grain boundary. Heat-induced grain growth decreases the number density of grain boundaries. Similarly, the improvement in oxidation resistance of sample b was attributed to the elimination of paths for oxygen diffusion. Upon passivation of the $\mathrm{Cu}$ surface with $\mathrm{Ag}$ layer, it served as a simple but effective barrier for oxygen diffusion as shown in Fig. 4c. In this case, $\mathrm{Cu}$ oxidation was more affected by the diffusion of $\mathrm{Cu}$ to the surface through the Ag layer. In the case of sample d, cumulative effects from the elimination of grain boundary through grain growth and the stuffing of grain boundary with covering Ag to close up the diffusion path are expected. Previous studies have already reported the stuffing of grain boundary with foreign metal, particularly for TiN with Al. ${ }^{15}$ Stuffing and grain growth cut off oxygen diffusion more effectively than that in sample c, though copper diffusion through the Ag layer determined the whole oxidation process after covering the surface with Ag layer.

Measurement of oxide thickness from FESEM images according to oxidation time validated these results about the different aspects of each sample (Fig. 5). The fitting lines in Fig. 5 implied that the oxide thickness of all samples was proportional to the square root of oxidation time. This indicates that the diffusion of reactants was the determining step for all oxidation reaction. Ag-free samples a and b underwent fast oxidation controlled by oxygen diffusion. On the other hand, Ag-covered samples c and d passed through a very slow oxidation that is controlled by copper diffusion through the Ag layer. The improvement of barrier property to oxygen diffusion through grain boundary stuffing and grain growth was attributed to the thinner oxide thickness of $\mathrm{d}$ compared to $\mathrm{c}$.

\section{Conclusions}

The AES and XRD analyses revealed that surface-restricted, high quality thin Ag layer could be obtained from the displacement reaction between electroplated $\mathrm{Cu}$ film and $\mathrm{Ag}$ ions. The study investigated the characteristics of displacement-deposited $\mathrm{Ag}$ layer as an oxidation barrier of $\mathrm{Cu}$. Oxidation of $\mathrm{Cu}$ in $\mathrm{Ag} / \mathrm{Cu} / \mathrm{TiN} / \mathrm{Ti} / \mathrm{Si}$ structure was efficiently blocked compared to $\mathrm{Cu} / \mathrm{TiN} / \mathrm{Ti} / \mathrm{Si}$, since the $\mathrm{Ag}$ passivation layer served as an oxygen diffusion barrier. Grain growth of $\mathrm{Cu}$ film induced through $400^{\circ} \mathrm{C}$ thermal annealing also contributed to block oxygen diffusion. Annealed $\mathrm{Ag} / \mathrm{Cu} / \mathrm{TiN} / \mathrm{Ti} / \mathrm{Si}$ 
structure showed the best performance, with the combined effects of grain growth and $\mathrm{Ag}$ stuffing of the grain boundaries of $\mathrm{Cu}$ film.

\section{Acknowledgments}

This work was supported by the Korea Science and Engineering Foundation through the Research Center for Energy Conversion and Storage ML.G. Chemical, Ltd., and also by the Institute of Chemical Processes and Inter-university Semiconductor Research Center in Seoul National University.

One of the authors, J. J. Kim, assisted in meeting the publication costs of this article.

\section{References}

1. S. P. Murarka, Mater. Sci. Eng., R., 19, 87 (1997).

2. P. C. Andricacos, C. Uzoh, J. O. Dukovic, J. Horkans, and H. Deligianni, IBM J. Res. Dev., 42, 567 (1998).
3. P. J. Ding, W. A. Lanford, S. Hymes, and S. P. Murarka, J. Appl. Phys., 74, 1331 (1993).

4. P. J. Ding, W. Wang, W. A. Lanford, S. Hymes, and S. P. Murarka, Nucl. Instrum. Methods Phys. Res. B, 85, 260 (1994)

5. X. Q. Zhao, Y. F. Han, and B. X. Liu, J. Appl. Phys., 90, 1638 (2001).

6. S. Hymes, S. P. Murarka, C. Shepard, and W. A. Lanford, J. Appl. Phys., 71, 4623 (1992).

7. P. J. Ding, W. Wang, W. A. Lanford, S. Hymes, and S. P. Murarka, Appl. Phys. Lett., 65, 1778 (1994).

8. P. J. Ding, W. A. Lanford, S. Hymes, and S. P. Murarka, Appl. Phys. Lett., 64, 2897 (1994).

9. P. J. Ding, W. A. Lanford, S. Hymes, and S. P. Murarka, J. Appl. Phys., 75, 3627 (1994).

10. W. A. Lanford, P. J. Ding, W. Wang, S. Hymes, and S. P. Murarka, Thin Solid Films, 262, 234 (1995).

11. F. A. Lowenheim, Electroplating, p. 356, McGraw-Hill, New York (1978).

12. J. J. Kim and S.-K. Kim, Appl. Surf. Sci., 183, 311 (2001).

13. J. J. Kim, S.-K. Kim, and J.-U. Bae, Thin Solid Films, 415, 101 (2002).

14. Y. Z. Hu, R. Sharangpani, and S.-P. Tay, J. Vac. Sci. Technol. A, 18, 2527 (2000).

15. A. Datta, K. T. Nam, S.-H. Kim, and K.-B. Kim, J. Appl. Phys., 92, 1099 (2002). 